\title{
Enhancement of Voltage Stability using SVC in PSCAD Software
}

\author{
Mohammad Shabir, Sarfaraz Nawaz, Ankit Vijayvargiya \\ Department of Electrical Engineering,Swami Keshvanand Institute of Technology, Management and \\ Gramothan, Jaipur-302017 (INDIA) \\ Email-mohammadshabir442@gmail.com
}

Received 20.12.2019 received in revised form 10.10.2020, accepted 12.10.2020

\begin{abstract}
In the power system network, the constant increase in demand for active and reactive power has restricted the possibility for network expansion which many times cause serious problems. The power system must be capable to keep acceptable voltage at all nodes in the network in a normal operating situation and during times of disturbance. Voltage instability is a severe concern in the system due to an increasing and unpredictable voltage drop. The research provided in this paper deals with many facts about the issue of voltage stability.

The major emphasis of this paper is to connect the FACTS device (Static VAR Compensator) at the system's sensitive location to rectify the voltage instability issue. The SVC enables the transmission lines to be loaded near to their thermal limits, pushing the power to travel through the optimal paths. The SVSI is used to identify the optimal location of SVC. IEEE 14 bus system is used as test system to check the efficacy of proposed technique, Different cases (like base, $5 \%$ increment in load, $5 \%$ decrement in load) are considered here also. In each case voltage deviation (VD) is calculated and found superior as compared to other techniques. It has been observed that SVSI give better location of SVC rather than other indexes.
\end{abstract}

Keywords - Voltage Stability, Voltage Deviation, Static var Compensator(SVC), Simplified Voltage Stability Index (SVSI), Relative Electric Distance (RED).

\section{INTRODUCTION}

The demand for electrical energy has very much intense in the present scenario. Around $27 \%$ of energy is wasted in India's distribution and transmission. India is the top country on the list of T\&D losses [1]. That took the energy system to the challenge of limitation of transmission and distribution. Such drawbacks have an even greater impact on efficient and safe energy supply in the transmission and distribution network of electrical power generally, Allowable voltage variance level is much lower, but the voltage level is not managed to the limit due to heavy load [2]. Wheneve there is a change in load or fault, the system voltage level changes. With the drop in voltage level, the reactive power demand increase. If the reactive power demand is not met, then it further decline in bus voltage resulting in the cascading effect on neighbouring regions[3]. When the system is working at its maximum capacity limits, Voltage collapse may occur. Voltage stability index predicts about the voltage collapse at weak bus[4]. As the disturbance arises in the system due to any abnormal condition of fault, it goes to transient oscillations. These unwanted oscillations can change the performance characteristic's of applications. Henc this is required to control and is done by the use of shunt FACTS device Static VAR Compensator (SVC) designed with auxiliary controllers. SVC will damp out the oscillations and improves the overall system stability[5]. This paper mainly deals on identifying the critical bus by calculating the simplified voltage stability index (SVSI) and voltage enhancement is justified on the critical bus after installation of SVC.

In this paper SVC device is used to improve voltage stability of the system. The optimal location of SVC is determined by SVSI. The IEEE 14 bus system is used as test system to check the efficiency of proposed SVSI. Two different loading level $(+5 \% \&-5 \%)$ is also considered in this paper.

\section{PROBLEM FORMULATION}

The voltage Instability has a very untoward effect on the reliability of the power system. The aim of this paper study is to eliminate the system's voltage deviation (VD) problem. Voltage deviation is made as small as possible to improve voltage at load bus. Objective function of VD minimization at load bus is defined as

$\mathrm{VD}=\min \left(\sum_{1}^{\mathrm{n}}\left|\mathrm{V}_{\mathrm{n}-\mathrm{V}_{\text {refn }}}\right|\right)$

where:

$\mathrm{n}=$ no. of load buses

$\mathrm{V}_{\mathrm{n}}=$ Voltage Magnitude of $\mathrm{n}^{\text {th }}$ bus

$\mathrm{V}_{\text {refn }}=$ Reference Voltage of $\mathrm{n}^{\text {th }}$ bus, usually set to 1 p.u.

This improvement of voltage at load buses of the power system is primary aim, which may be achieve by the connection of SVC at optimal location. SVC control system is modeled, tuned and 
optimally placed to analyze the behavior in both steady and dynamic conditions of the system.

\section{MATHEMATICAL MODELLING OF SVC:}

The term SVC was used for the shunt linked compensator, which is centered on a thyristor without gate turn-off [14]. According to the IEEE standard SVC is defined as a shunt connected static VAR generator or an absorber whose output is modified to exchange capacitive or inductive current in order to maintain or regulate different electrical power system parameters. In Figure 5, PSCAD introduced the 14 bus test system to run simulations for the SVC.

Appropriate SVC model is needed to explore the impact of SVC on the power system. Here SVC is observed as shunt connected variable susceptance $\left(\mathrm{B}_{\mathrm{SVC}}\right)$. That automatically transforms to gain voltage balance. Algebraic equations are developed with respect to sinusoidal voltage like as

$I_{S V C}=j B_{S V C} V$

The fundamental frequency TCR equivalent reactance $X_{\mathrm{TCR}}$ :

$X_{T C R}=\pi X_{L} /(\delta-\operatorname{Sin} \delta)$

Where $\delta=2(\pi-\alpha), \delta$ is conduction angle and $\alpha$ is firing angle. TCR equivalent reactance $X_{T C R}$ is firing angle $(\alpha)$ terms -

$X_{T C R}=\frac{\pi X_{L}}{2(\pi-\alpha)-\sin \alpha}$

$X_{C}=\frac{1}{W_{c}}$

at $\alpha=90 \circ, \mathrm{X}_{\mathrm{TCR}}=\mathrm{X}_{\mathrm{L}}$ means TCR is in fully conducting mode, while at $\alpha=180 \circ, \mathrm{X}_{\mathrm{TCR}}=\infty$ means TCR is in blocking mode. Functional reactance of SVC is the parallel combination of $\mathrm{X}_{\mathrm{TCR}}$ and $\mathrm{X}_{\mathrm{C}}$ as.

$$
X_{S V C}=\frac{\pi X_{C} X_{L}}{X_{C}[2(\pi-\alpha)+\sin 2 \delta]-\pi X_{L}}
$$

$$
\begin{aligned}
& Q_{S V C} \\
& =-V_{K}^{2}\left\{\frac{X_{C}[2(\pi-\alpha)+\sin 2 \alpha]-\pi X_{L}}{\pi X_{C} X_{L}}\right\}
\end{aligned}
$$

As the reactive power demand at the bus varies, the susceptance $\left(\mathrm{B}_{\mathrm{SVC}}\right)$ varies between the limits. however, Reactive power is proportional with the bus voltage $\left(\mathrm{V}_{\mathrm{K}}\right)$ square. As the voltage changes, thus, the reactive power generated changes.

\section{VOLTAGE STABILITY INDICES}

In order to detect the loadability of the system, stability indices are proposed. In a power system, indices offer data on the position of voltage instability. Such indices can either show a power system's critical bus or the stability of each line linked in an interconnected network between two buses or measure a system's voltage stability margins.

\subsection{Voltage Stability Index (VSI)}

This method suggests an index based on the power flow equation solution [16 ]. Assumptions are made in this approach based on the design of thevenin shown in figure 2 .

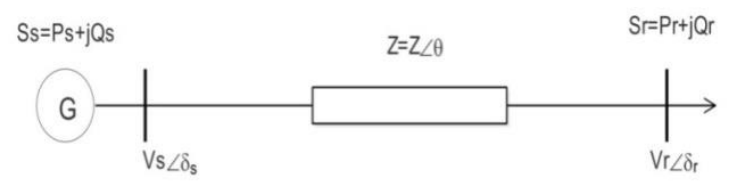

Figure 1: Power system presented by thevenin's equivalent

The amplitude of the load bus voltage is equal to the amplitude of the voltage drop in thevenin impedance $(Z)$ in the maximum power transfer state [16]. These are the assumptions used in this method: (a) The total of the actual voltage drop values for each row is the distance to a generator through the short distance from node to generator. (b) If some generators have the same distance it is okay to take any of them as closest. The VSI for a bus $\mathrm{n}$ is defined as

$$
V S I_{n}=\frac{V_{n}}{\Delta V_{n}}
$$

where $\mathrm{V}_{\mathrm{n}}$ is voltage at the bus $\mathrm{n}$ and $\delta \mathrm{V}_{\mathrm{n}}$ is an guess-work of the voltage drop at impedance and can be calculated as-

$$
\begin{aligned}
\Delta V_{n}^{(i)}(t)=\min \Delta & V_{n}^{(i)}(t) \\
& =\min \sum_{b-1}^{\left(n_{j}-1\right)} \mid V_{b}(t) \\
& -V_{b+1}(t) \mid
\end{aligned}
$$

An iterative algorithm is often used to construct a matrix to help identify the nearest bus generator [15]. Drawbacks of this method are as: (1) Due to large no iterations, it has high computational costs.. (2) Because of the limits of the generator, the tree matrix must be determined for each topological transition, which is difficult in the large power system.

\subsection{Simplified Voltage Stability Index (SVSI):}

This method is based on the RED theory, which informs us about the nearest generator to load bus.

4.2.1 Relative Electrical Distance (RED):

If you look at a process where $\mathrm{n}$ is the total number of $1,2 \ldots \mathrm{g}$ buses. $\mathrm{g}$ is the number of generator buses and $\mathrm{g}+1, \ldots ., \mathrm{n}$ is the number of load buses left $(\mathrm{n}-\mathrm{g})$. The addmittance matrix of for a given system is:

$$
\left[\begin{array}{l}
\mathrm{I}_{S} \\
\mathrm{I}_{\mathrm{L}}
\end{array}\right]=\left[\begin{array}{cc}
\mathrm{Y}_{\mathrm{SS}} & \mathrm{Y}_{\mathrm{SL}} \\
\mathrm{Y}_{\mathrm{LS}} & \mathrm{Y}_{\mathrm{LL}}
\end{array}\right]\left[\begin{array}{c}
\mathrm{Y}_{\mathrm{S}} \\
\mathrm{Y}_{\mathrm{L}}
\end{array}\right](8)
$$


Here:- $\left[\mathrm{I}_{\mathrm{S}}\right]=\left[\mathrm{I}_{1}, \ldots, \mathrm{I}_{\mathrm{g}}\right] \mathrm{t}=$ injected currents of generator buses, $\left[\mathrm{I}_{\mathrm{L}}\right]=\left[\mathrm{I}_{\mathrm{g}+1}, \ldots, \mathrm{I}_{\mathrm{n}}\right]=$ Injected Load Bus Currents,

$\left[\mathrm{V}_{\mathrm{S}}\right]=\left[\mathrm{V}_{11}, \ldots, \mathrm{V}_{\mathrm{g}}\right]=$ complex generator bus voltage, $\left[\mathrm{V}_{\mathrm{L}}\right]=\left[\mathrm{V}_{\mathrm{g}+1}, \ldots, \mathrm{V}_{\mathrm{n}}\right]=$ complex load bus voltage and $\left[\mathrm{Y}_{\mathrm{SS}}\right],\left[\mathrm{Y}_{\mathrm{SL}}\right],\left[\mathrm{Y}_{\mathrm{LS}}\right],\left[\mathrm{Y}_{\mathrm{LL}}\right]=$ The relevant parts of the Y-Bus matrix network.

To represent the relationship between generator bus and load bus voltages mathematically, we should drive the $F_{L S}$ matrix as shown in the equation below.

$$
\left[\begin{array}{c}
V_{L} \\
I_{S}
\end{array}\right]=\left[\begin{array}{cc}
Z_{L L} & F_{L S} \\
K_{S L} & Y_{S S}^{\prime}
\end{array}\right]\left[\begin{array}{c}
I_{L} \\
V_{S}
\end{array}\right]
$$

Here:- $\left[\mathrm{F}_{\mathrm{LS}}\right]=-\left[\mathrm{Y}_{\mathrm{LL}}\right]^{-1}\left[\mathrm{Y}_{\mathrm{LS}}\right],\left[\mathrm{Y}_{\mathrm{SL}}\right]=\left[\mathrm{Y}_{\mathrm{SL}}\right]\left[\mathrm{Y}_{\mathrm{LL}}\right]^{-1}$

$\mathrm{F}_{\mathrm{LS}}$ is a complex matrix, The columns correspond to the number of the generators and the rows correspond to the number of the load bus. This matrix is the relationship between the voltage of the load bus and the voltage of the source bus. Ideal generation proportions are obtained from abs[ $\left.\mathrm{F}_{\mathrm{LS}}\right] \mathbf{5}$. matrix, also known as desired generation proportions matrix $\left[\mathrm{D}_{\mathrm{LS}}\right]$.

$$
\left[D_{L S}\right]=\operatorname{abs}\left[F_{L S}\right]
$$

$\left[D_{L S}\right]$ tells about the location of load buses with respect to generators, which is popularly known as RED. The $[R E D]$ is obtained from $\left[D_{L S}\right]$ matrix as

$$
[R E D]=\mathrm{I}-\left[D_{L S}\right]
$$

where $\mathrm{I}$ is unity matrix of size $\mathrm{L} \times \mathrm{S}$.

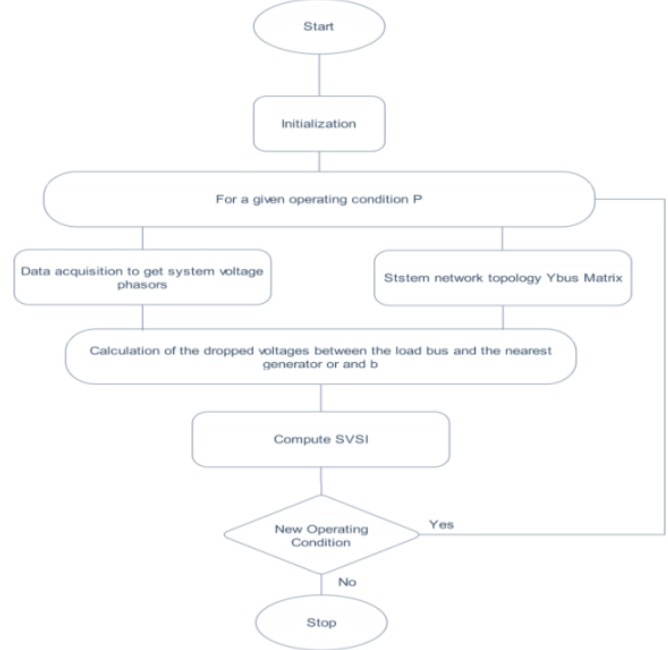

Figure 2: Flow-chart of SVSI

In Fig. 3 the proposed SVSI index is simply a measurement-based VSI which requires data from bus monitoring. Simply, the proposed technique requires voltage phasers to find a region sensitive to voltage instability in all the buses of the examined power system.

As electrical distance is found with the $\left[\mathrm{R}_{\mathrm{TH}}\right]$, the voltage drop $\left(\Delta \mathrm{V}_{\mathrm{n}}\right)$ is:

$\Delta V_{n}=\sum_{b-1}^{n_{j}-1}\left|\vec{V}_{b}-\vec{V}_{b+1}\right| \cong\left|\vec{V}_{g}-\vec{V}_{l}\right|$
Where: $\mathrm{V}_{\mathrm{g}}=$ Nearest generator voltage, $\mathrm{V}_{\mathrm{l}}=$ Analyzed load voltage, $\Delta \mathrm{V}_{\mathrm{n}}$ is a simplification of the actual approach defined in [17]. Most of the indices of voltage stability are somewhat inaccurate due to the different approximation [18].

But to improve its reliability, SVSI relies on other physical parameters (amplitude and voltage or power phase). To enhance the voltage drop state of any bus, correction factor $(\beta)$ for the SVSI is introduced as:

$$
\beta=1-\max \left(\left|V_{m}\right|-\left|V_{l}\right|\right)^{2}
$$

The correction factor is aligned with the highest voltage magnitude difference. Now the SVSI is given as

$$
\operatorname{SVSI}_{i}=\frac{\Delta V_{i}}{\beta * V_{i}}
$$

The entire process become simple due to the elimination of the computational activity, so it is called the ' Simplified ' voltage stability index.

\section{SIMULATION RESULTS AND DISCUSSIONS}

The IEEE 14 bus system was used as a test system to monitor SVSI's proposed effectiveness. The PSCAD software modeled the IEEE 14 bus model. Here single line diagram of the IEEE 14 bus test system consists of five synchronous machines, including three synchronous condensors for reactive power support in figure 5. There are 17 transmission lines and fourteen buses with eleven loads. With a base of 100 MVA per unitizing, a brief knowledge about the characteristics of each source is given.

\subsection{Base Case:}

In base case simulation, we obtain the power flow solution of system as table 1 and obtained results are tabulated to calculate SVSI of each load Bus under steady state condition.

Step-1: Determine the nearest generator of the load bus by using RED concept. RLG matrix helps in calculating the related electrical distance.

Step-2 Estimating the SVSI. According to the $\mathrm{R}_{\mathrm{LG}}$ Matrix, Bus 4 is nearest to the GEN 2. So the voltage drop from GEN 2 to Bus $\mathrm{x}$ is calculated as:

$\Delta \mathrm{V}_{\mathrm{x}}^{2}=1.001-0.9711$

$$
\Delta V_{x}^{2}=\left|\vec{V}_{2}-\vec{V}_{x}\right|
$$

Correction factor is calculated by using of highest difference of voltages as:

$$
\begin{gathered}
\beta=1-\left(\left|V_{m}\right|-\left|V_{t}\right|\right)^{2} \\
\beta=0.9914
\end{gathered}
$$

According to the definition of SVSI, index for load bus 4 is

$$
S V S I_{x}=\frac{\Delta V_{x}^{2}}{\beta * V_{x}}=0.0243
$$


Here $x=$ Bus 4. Similarly SVSI is calculated for other load buses as shown in table 2 .

Table 1: Voltage Profile under Normal Condition (in pu)

\begin{tabular}{|c|c|}
\hline Bus No. & Voltage(pu) \\
\hline 1 & 1 \\
\hline 2 & 1.001 \\
\hline 3 & 1 \\
\hline 4 & 0.9711 \\
\hline 5 & 0.9703 \\
\hline 6 & 1.008 \\
\hline 7 & 0.993 \\
\hline 8 & 1.005 \\
\hline 9 & 0.9881 \\
\hline 10 & 0.9836 \\
\hline 11 & 0.9919 \\
\hline 12 & 0.9919 \\
\hline 13 & 0.9864 \\
\hline 14 & 0.9681 \\
\hline
\end{tabular}

Table 2: SVSI of Load Buses

\begin{tabular}{|c|c|}
\hline Load Bus & SVSI \\
\hline 4 & 0.0309 \\
\hline 5 & 0.0317 \\
\hline 7 & 0.0121 \\
\hline 9 & 0.0172 \\
\hline 10 & 0.0249 \\
\hline 11 & 0.0163 \\
\hline 12 & 0.0163 \\
\hline 13 & 0.0221 \\
\hline 14 & 0.043 \\
\hline
\end{tabular}

Table 3: Voltage profile After connecting SVC in Normal condition

\begin{tabular}{|c|c|c|}
\hline $\begin{array}{c}\text { Bus } \\
\text { No. }\end{array}$ & Without SVC & With SVC \\
\hline 1 & 1 & 1 \\
\hline 2 & 1.001 & 1.002 \\
\hline 3 & 1 & 1.001 \\
\hline 4 & 0.9711 & 0.9736 \\
\hline 5 & 0.9703 & 0.9722 \\
\hline 6 & 1.008 & 1.012 \\
\hline 7 & 0.993 & 0.9994 \\
\hline 8 & 1.005 & 1.006 \\
\hline 9 & 0.9881 & 0.9996 \\
\hline 10 & 0.9836 & 0.9938 \\
\hline 11 & 0.9919 & 0.9989 \\
\hline 12 & 0.9919 & 0.9989 \\
\hline 13 & 0.9864 & 0.9961 \\
\hline 14 & 0.9681 & 0.9988 \\
\hline
\end{tabular}

In table no.2 SVSI for all the load buses is calculated is shown. The minimum SVSI value is found at bus no $14(0.043)$. Hence, the bus no 14 will be optimal location for SVC installation.

As we can see in table 3 , the SVC voltage profile is enhanced. Non-SVC voltage deviation is 0.1416 . Table-3 shows that after SVC installation the voltage profile of each bus is improved. Upon activation of SVC, the voltage deviation is also reduced until 0.0477 .

\subsection{CASE-I: With 5\% increment in all load level}

In this case, the load level of IEEE 14 bus system has been increased by $5 \%$. The table no. 5 exhibits the results of voltage level of 14 bus system before and after SVC allocation.

The voltage level decreases at all load buses after the increase in load, but the voltage deviation increases. Deviation in base case voltage profiles was 0.1416 , which increased to 0.1658 . Up to 0.0642 voltage deviation is reduced after connecting SVC at bus 14 .

\subsection{CASE-II: With 5\% decrement in all load} level

Decrement in the load by $5 \%$ is done and a rise in bus voltages is seen. After connecting SVC voltage at load buses are improved.

Voltage level of all buses is increase with condition of $5 \%$ decrease in load and voltage deviation is decreased which is 0.1076 . But it may further be decreased by allocating the SVC at bus 14. After SVC allocation voltage deviation is again decreased up to 0.0372 .

Table 4: Improvement in Voltage in condition of 5\% increment in load

\begin{tabular}{|c|c|c|}
\hline Bus No. & Without SVC & With SVC \\
\hline 1 & 1 & 1 \\
\hline 2 & 1.001 & 1.001 \\
\hline 3 & 0.999 & 0.9997 \\
\hline 4 & 0.9696 & 0.9724 \\
\hline 5 & 0.9691 & 0.9714 \\
\hline 6 & 1.007 & 1.011 \\
\hline 7 & 0.991 & 0.9982 \\
\hline 8 & 1.004 & 1.006 \\
\hline 9 & 0.9849 & 0.9979 \\
\hline 10 & 0.9804 & 0.9919 \\
\hline 11 & 0.9896 & 0.9974 \\
\hline 12 & 0.99 & 0.9978 \\
\hline 13 & 0.984 & 0.995 \\
\hline 14 & 0.9642 & 0.9988 \\
\hline
\end{tabular}

\section{CONCLUSION AND FUTURE SCOPE}

A new Index (SVSI) was introduced in this paper to decide SVC's optimal position. The paper's goal is to improve power system voltage stability under normal and abnormal conditions by reducing voltage deviation. IEEE 14 bus system was used as a test system to verify the efficacy of the proposed technique. Three different cases, i.e. base case, $5 \%$ load increase and 5\% load decrease are considered here. The voltage deviation of the IEEE 14 bus system is also calculated and compared to other techniques after SVC installation. It was observed that SVSI provides optimal SVC location for IEEE 14 bus system (i.e. bus no. 14) compared 
to any other techniques. For all different cases the SVC has work superior. The whole system has been simulated in PSCAD software.

Table 6: Improvement in Voltage in condition of 5\% Decrease in load

\begin{tabular}{|c|c|c|}
\hline $\begin{array}{l}\text { Bus } \\
\text { No. }\end{array}$ & $\begin{array}{l}\text { Without } \\
\text { SVC }\end{array}$ & With SVC \\
\hline 1 & 1 & 1 \\
\hline 2 & 1.002 & 1.002 \\
\hline 3 & 1.001 & 1.001 \\
\hline 4 & 0.9725 & 0.9746 \\
\hline 5 & 0.9714 & 0.9731 \\
\hline 6 & 1.009 & 1.012 \\
\hline 7 & 0.995 & 1.001 \\
\hline 8 & 1.005 & 1.007 \\
\hline 9 & 0.9912 & 1.001 \\
\hline 10 & 0.9869 & 0.9958 \\
\hline 11 & 0.9943 & 1 \\
\hline 12 & 0.994 & 1 \\
\hline 13 & 0.989 & 0.9975 \\
\hline 14 & 0.9721 & 0.9988 \\
\hline
\end{tabular}

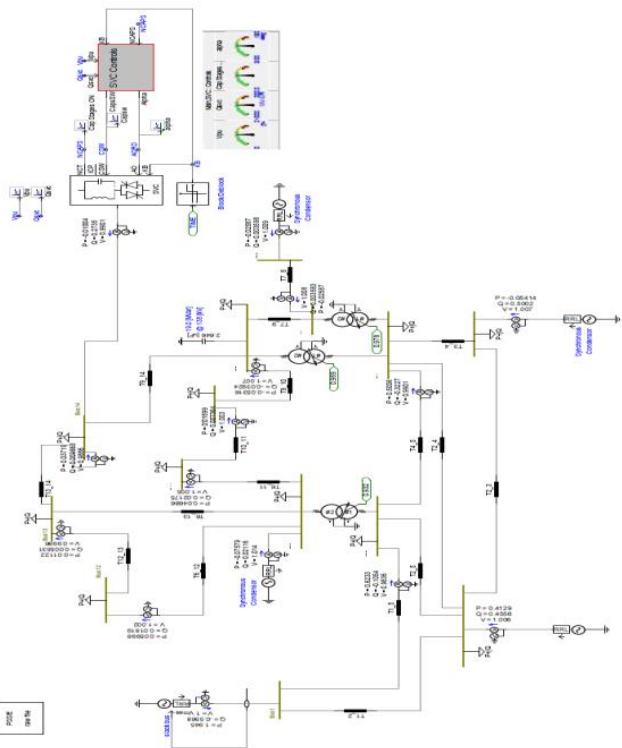

Figure 5: IEEE 14 Bus Simulation model in PSCAD Software

\section{REFERENCES}

[1] M. J. P. S. Arora, Power transmission and distribution losses in india-a study report, Journal Current Science 20 (1).

[2] J. Lakkireddy, R. Rastgoufard, I. Leevongwat, P. Rastgoufard, Steady state voltage stability enhancement using shunt and series facts devices, in: 2015 Clemson University Power Systems Conference (PSC), IEEE, 2015, pp. 1-5.

[3] P. Tomar, A. K. Singhal, Power system stability enhancement using upfc, Journal of Instrumentation Technology and Innovations 8 (3) (2019) 1-7.

[4] Choudekar, Pallavi, and Divya Asija. "Prediction of voltage collapse in power system using voltage stability indices." Proceeding of international conference on intelligent communication, control and devices. Springer, Singapore, 2017.

[5] P. Somasundaram, V. Jayakumar, K. Sundararaju,
Congestion management using svc under deregulated power system, International Journal of Pure and Applied Mathematics 118 (20) (2018) 2307-2317.

[6] N. Mithulananthan, C. A. Canizares, J. Reeve, G. J. Rogers, Comparison of pss, svc, and statcom controllers for damping power system oscillations, IEEE transactions on power systems 18 (2) (2003) 786-792.

[7] Y. Ou, C. Singh, Assessment of available transfer capability and margins, IEEE Transactions on Power Systems 17 (2) (2002) 463-468.

[8] S. Gerbex, R. Cherkaoui, A. J. Germond, Optimal location of multi-type facts devices in a power system by means of genetic algorithms, IEEE transactions on power systems 16 (3) (2001) 537-544.

[9] Choudekar, Pallavi, S. K. Sinha, and Anwar Siddiqui. "Optimal location of SVC for improvement in voltage stability of a power system under normal and contingency condition." International Journal of System Assurance Engineering and Management 8.2 (2017): 1312-1318.

[10] J. Dixon, L. Moran, J. Rodriguez, R. Domke, Reactive power compensation technologies: State-of-the-art review, Proceedings of the IEEE 93 (12) (2005) 2144 2164.

[11] B. Mahdad, T. Bouktir, K. Srairi, Strategy of location and control of facts devices for enhancing power quality, in: MELECON 2006-2006 IEEE Mediterranean Electrotechnical Conference, IEEE, 2006, pp. 10681072 .

[12] D. Mondal, A. Chakrabarti, A. Sengupta, Optimal placement and parameter setting of svc and tcsc using pso to mitigate small signal stability problem, International Journal of Electrical Power \& Energy Systems 42 (1) (2012) 334-340.

[13] M. N. Nwohu, Voltage stability improvement using static var compensator in power systems, Leonardo Journal of Sciences 8 (14) (2009) 167-172.

[14] D. T. Kaur, S. Kakran, Transient stability improvement of long transmission line using svc, International Joural of Advanced research in Electrical, Electronics and Instrumentation Enginering 1 (4)

[15] P. Sahu, A. Pachori, M. Simulink, Power factor correction using svc with fuzzy logic controller, International Journal of Enhanced Research in Science Technology \& Engineering 2 (4) (2013) 52-57.

[16] P. Kessel, H. Glavitsch, Estimating the voltage stability of a power system, IEEE Transactions on power delivery 1 (3) (1986) 346-354.

[17] B. Gen^et, J.-C. Maun, Voltage-stability monitoring using wide-area measurement systems, in: 2007 IEEE Lausanne Power Tech, IEEE, 2007, pp. 1712-1717.

[18] M. Dester, C. A. Castro, Multi-criteria contingency ranking method for voltage stability, Electric Power Systems Research 79 (1) (2009) 220-225.

[19] J. Vanishree, V. Ramesh, Optimization of size and cost of static var compensator using dragonfly algorithm for voltage profile improvement in power transmission systems, International Journal of Renewable Energy Research (IJRER) 8 (1) (2018) 56-66.

[20] R. Agrawal, S. Bharadwaj, D. Kothari, Optimal location and sizing of svc considering transmission loss and installation cost using tlbo, in: 2015 Annual IEEE India Conference (INDICON), IEEE, 2015, pp. 1-6.

[21] V. K. Shende, P. Jagtap, Optimal location and sizing of static var compensator (svc) by particle swarm optimization (pso) technique for voltage stability enhancement and power loss minimization, proceedings of International Journal of Engineering Trends and Technology (IJETT)-Volume4 Issue6-June. 